\title{
Doctor Rafael Gómez-Cuevas
}

\section{Jácome A.}

Expresidente y Miembro Honorario de la Asociación Colombiana de Endocrinología, Diabetes y Metabolismo. Miembro del Comité Editorial de la Revista Colombiana de Endocrinología, Diabetes y Metabolismo.

Hace pocos meses volví a saber de las actividades de Rafael GómezCuevas (para algunos amigos "el Marqués de Cuevas") pues le había perdido la pista desde que se fue a vivir a su querida España. Esto ocurrió porque nos había enviado una revisión muy detallada sobre la historia del aceite de oliva y de su impacto en la saludable dieta mediterránea, un trabajo muy de su estilo que fue publicado en la revista de la ACE.

Me conmovió saber que en mayo de 2019 se nos fue, siendo octogenario. Rafael estudió bachillerato en el Colegio Mayor de Nuestra Señora del Rosario en Bogotá, comenzó estudios de medicina en la Universidad Nacional, aunque los terminó en la Universidad Complutense de Madrid, España. Entre 1959 y 1961 se entrenó en Medicina Interna y Endocrinología en el Hospital Clínico de Madrid, cátedra del profesor Luis Felipe Pallardo Peinado. Veinte años más tarde regresaría becado por el Ministerio Español de Asuntos Exteriores para realizar un entrenamiento en Obesidad y Diabetes, en el Hospital Clínico de San Carlos, en Madrid.

En España conoció a Ketty, española con quien tuvo varios hijos. En su segundo matrimonio con una dama colombiana tuvo otro descendiente. Entiendo que en sus últimos años vivía en la península ibérica.

En Bogotá fue Jefe de Endocrinología del Hospital de la Samaritana -entidad que le dio el título de profesor emérito- y actuaba como profesor auxiliar de la Universidad Javeriana cuando lo conocí. Tenía muchos amigos, pero desde la Samaritana lo fue especialmente con Roberto De Zubiría Consuegra, compañero de andanzas bohemias con quien compartía su gusto por la estética, el humanismo y la bonhomía, amén del amor por la medicina y el estudio de la ciencia.

Tenía aspecto de prócer, o más bien de catedrático español de antiguas épocas, con su barba bien cuidada y abundante cabellera, ya blanca con el pasar de los años. Aunque daba la impresión de no tomar la vida muy en serio, era un trabajador incansable. Realizó numerosas actividades como conferencista, autor de libros, organizador de congresos, fundador y directivo de sociedades científicas en el campo de su especialidad. Apoyaba decididamente la integración hispanoamericana, tanto que de las 26 sociedades científicas a las que perteneció, la mayoría eran de la región latinoamericana o de la Madre Patria. Sus dos condecoraciones las obtuvo en España y en Venezuela. Fue también miembro de la Sociedad Hispanoamericana de Letras.

Me sucedió en la presidencia de la Sociedad Colombiana de Endocrinología y en la dirección de la revista, que bajo un nuevo nombre actualmente publica la ACE. Las reuniones durante su presidencia las hacía en la "Casa España", de Teusaquillo, famosa por su comida ibérica y por sus estupendos vinos de la Rioja y de la Rivera del Duero. Le gustaba la cerveza, no pedía una sino dos, una fría y otra "al clima" y las mezclaba antes de ingerirlas. Era experto en preparar refajos.

Compartimos muchos años en la industria farmacéutica como directores médicos, él estuvo todo el tiempo en la firma Boehringer Mannheim que tenía productos endocrinológicos y reactivos de laboratorio. Ese cargo le sirvió para ayudar a las sociedades científicas, organizar numerosos cursos, congresos y patrocinar o escribir libros. Creó incluso la Asociación de Directores Médicos de la Industria Farmacéutica (ADMIF), de la cual fue el primer y único presidente. De la fundación de dicha asociación recuerdo un almuerzo en un club social de Bogotá, que en medio de copas y jolgorio se prolongó hasta horas de la noche, pues había un piano y Jorge Guzmán Toledo ("Boliche"), otro extraordinario ser humano y a la sazón el director médico de Bayer, era aficionado a tocar este instrumento y nos deleitó con su música. La Asociación se acabó rápidamente porque los gerentes (o sea, nuestros jefes) consideraron que les estábamos montando un sindicato.

Ayudó a fortalecer la Asociación Colombiana de Medicina Interna en el llamado "Gran Congreso" que dirigió Hernando Sarasti, y luego Fernando Chalem. De él recuerdo siete simposios que realizaba anualmente en el antiguo Hotel Hilton de Bogotá, que patrocinaba su empresa farmacéutica interesada en los "Factores de Riesgo Coronario". Por supuesto que asistíamos los especialistas y también los médicos generales, pero en particular el recinto se llenaba con un número impresionante de dietistas y nutricionistas.

Su interés académico primordial se centró en la diabetes, pero más específicamente en la obesidad. Su actividad más intensa en relación con esta patología la desarrolló en el tercer milenio. Fue fundador y presidente honorario de la Asociación Colombiana de Obesidad y Metabolismo (ASCOM), delegado por Colombia a la IASO (International Association for the Study of Obesity), en la cual fue vicepresidente y miembro de su Education \& Management Obesity Task Force, director ejecutivo del programa COBELAT (Certificación Obesidad en América Latina) y coordinador del proyecto SCOPE/COBELAT para Latinoamérica, coordinador del Comité de Ética de la FLASO, coordinador del Grupo de Investigación Nuevamérica, presidente de la Federación Latinoamericana de Sociedades de Obesidad (FLASO) y presidente honorario de la Sociedad Bolivariana de Endocrinología, vicepresidente de la Sociedad Latinoamericana de Ateroesclerosis (SOLAT) y presidente de la Sociedad Hispanoamericana de Nutrición, Capítulo Colombia.

Como estupendo conferencista que era, le gustaba disertar sobre el impacto de la obesidad (o la presencia de síndromes endocrinos) en la literatura y el arte, o hacer una "ronda endocrinológica por el Museo del Prado". Alguna vez me tocó servir de comentarista en una de estas conferencias en la Academia Nacional de Medicina, y para ello me basé en mi lectura del libro Search the Scriptures: Modern Medicine and Biblical Personages, del profesor canadiense de ginecología endocrina del Medical College of Georgia (USA) Robert B. Greenblatt, que describía los casos endocrinos que según él aparecían en el libro sagrado.

Entre sus libros podemos citar, Obesidad, una autopista hacia el infarto, Dulce diabetes sin amargo destino, Obesidad a la carta y Trastornos de la conducta alimentaria y sus pequeñas perversiones. Fue editor de un libro de la ACE titulado Monografía sobre diabetes, que tuvo amplia difusión. Pero por su interés polifacético y romántico, también escribió libros de poesía como La deseada orilla del amor, novelas como Eterno camino hacia un destino o Dados sobre la piel de toro (esta última novela es histórica, transcurre durante la Guerra Civil Española), monografías como La endocrinología de Venus y cuentos como Mujer de Arena y Adipocuentos.

Gómez-Cuevas era estudioso del adipocito, pero le disgustaba que lo tuvieran como negocio. Muchas veces criticó algunos de estos centros, a los que llamaba antros. Me imagino que llegó a conocer que la industria de los alimentos y de las dietas es un multimillonario negocio en los Estados Unidos y en el mundo.

Descanse en paz, señor Marqués. 